\title{
Creative Nonfiction and the Research Method
}

\section{Creative Nonfiction}

This is a research monograph which takes the form of a novel. This novel is filled with ethnographic data reconstructed in accordance with socialscientific research principles.

The method of writing which brings together empirical material and fiction has been named "creative nonfiction" (Caulley 2008). It grew of "the new journalism" (see Pauly 2014) that emerged in the 1960s and 1970s. Other authors claim that the methods of "experimental writing" emerged from feminist and postmodernist criticisms of earlier qualitative research reporting as "deliberate attempts to reposition the author and the reader" (Ezzy 2002: 151). Be that as it may, the principle of creative nonfiction resides in combining the most reliable information with an imaginative and narrative approach.

The model has spread in reporting qualitative research, particularly since the 1990s among those who wanted to exercise the sociological imagination in a vivid yet empirically grounded way. As argued by major literary theorists (e.g. Genette 1990; Schaeffer 2014), there are numerous borrowings, exchanges, and intersections between fictional and factual narratives:

If one took into consideration actual practice, one would have to admit that there exists neither pure fiction nor history so rigorous as to abstain from all 'plotting' and all novelistic devices whatsoever, and therefore that the two domains are neither so far apart nor so homogeneous as they might appear. (Genette 1990: 772)

(C) The Author(s) 2019

J. Kotišová, Crisis Reporters, Emotions, and Technology, https://doi.org/10.1007/978-3-030-21428-9_6 
Within the realms of sociology and anthropology, intimate links between the disciplines and literature and the enriching potential of artistic inspiration have been recognized, for example, by Zygmunt Bauman and Clifford Geertz:

we have to come as close as the true poets do to the yet-hidden human possibilities; and for that reason we must need to crush the walls of the obvious and self-evident, of that prevailing ideological fashion of the day whose commonality is taken for the proof of its sense. Demolishing such walls is as much the sociologist's as it is the poet's calling, and for the same reason: they lie about human potential while barring the disclosure of their own bluff. (Bauman 2000: 79-80)

It is not clear just what 'faction,' imaginative writing about real people in real places at real times, exactly comes to beyond a clever coinage, but anthropology is going to have to find out if it is to continue as an intellectual force in contemporary culture-if its mule condition (trumpeted scientific mother's brother, disowned literary father) is not to lead to mule sterility. (Geertz 1988: 141)

According to Douglas Ezzy, utilization of the links between fiction and fact "does not lead to relativist scepticism but to a more sophisticated approach to social research" (Ezzy 2002: 149). Such "a science that is aesthetic, moral, ethical, moving, rich, and metaphoric as well as avantgarde, transgressing, and multivocal" (Richardson 1997: 16; quoted in Ezzy 2002: 149), however, poses some challenges both to the author and to the reader.

In particular, the research monograph taking the form of a novel based on ethnographic data combines factual and fictional narrative: "[F]actual narrative and fictional narrative behave differently towards the story which they 'report' by the mere fact of this story's (supposedly) being in one case 'truthful' (as Lucian put it), in the other case fictional, that is, invented by someone. ... What counts here is the official status of the text and its reading horizon" (Genette 1990: 756-757). Using terms borrowed from literary theory, the discourse of the book combines fictional and factual parts of a plot (that, if taken chronologically, would be quite clearly divided by the first few lines of "An Introduction to Crisis Reporting: Setting Out": James' recollections are usually real, while his present situation is fictitious) (Culler 1997). The combination of fact and fiction in one discourse thus makes it complicated to determine the "reading horizon." 
What follows therefore can be read as a guide for the reader who is uncertain about the reading horizon.

\section{The Factual in the Fictional in the Factual Narrative}

On the one hand, if we consider only the ethnographic data and the reality of the research monograph (i.e. leaving aside James' own story), the narrative is factual. One thing that distinguishes factual and fictional narratives is the relationship between the author, narrator, and character (Genette 1990). In the research monograph, the author is identical to the narrator (me), while the main character is someone else (James):

\section{Author $=$ narrator $\neq$ character}

This is to say that I, as the author, seriously adhere to the story, for which I assume responsibility (Genette 1990). It is precisely this unity of author and narrator that defines factual narrative; "this is so whatever the tone, truthful or otherwise, of the syuzhet or, if you prefer, whatever the status, fictional or otherwise, of the fabula" (Genette 1990: 766-767).

Furthermore, the journalists' (again, leaving aside James and Sophie Schlesinger) stories are referential and advance claims of referential truthfulness (Schaeffer 2014). Regardless of its creativity, even creative nonfiction can and must remain true to the validity and integrity of the information it contains. (In principle, one could even insist that thorough anonymization does not deform reality less than adding an explicitly fictional character; see Gutkind 1997.) "For the qualitative researcher writing creative nonfiction, the result is only as rigorous as the rigor of the research and the data on which the writing is based" (Caulley 2008: 445).

In this sense, this book is a kind of "historical narrative" (Genette 1990). The factual plane of the work consists of the factuality of, first, the research monograph written by a researcher adhering to principles of ethnographic research, and, second, the ethnographic data reconstructed in the way explained below.

On the other hand, between the ethnographic data and the reality of the research monograph, there is the imaginary story of James who, while enacting his own story, tells/recalls the story of his colleagues based on their own narratives:

Author $\neq$ narrator $\neq$ character 
The presence of a metadiegetic narrative- a secondary narrative, or a story told, dreamt, or imagined by a character-is a plausible indication of fictionality. In this sense, the narrative is a "heterodiegetic fiction" (Genette 1990). The fictional plane is delimited by the story of James, Fred, Sophie Schlesinger, the flight attendants, the other passengers, the catastrophe, San Lorenzo, and ice-nine (which does not mean, of course, that the characters and the scene do not have any model in reality; quite the oppositesee later in this chapter).

While we tend to define factual and fictional narratives as a pair of opposites, their pure forms are only to be found in a test tube, so that one cannot set one in opposition to the other (Genette 1990; Schaeffer 2014; see above). This, of course, means neither suggesting that fact itself is a mode of fiction, as some have done, nor ruling out ontological realism. The fact that discourse and narrative are constructions does not necessarily mean that fact is fiction or the constructed nature of narratives does not make them fictional (Schaeffer 2014).

\section{Where the Fictional Narrative Is Not an End in Itself}

Consequently, while the distinction between facts, lies, half-truths, and inventions matters, the fictional and factual genres are permeable, and this book-its argument and conclusions as presented in the "Emotions, Technology, and Crisis Reconsidered: Ending"-attempts to profit precisely from the intersections of the factual and fictional narratives. There are various types of intersections: mainly those that happen in James' head and those that happen in the story - at the airport or in the airplane. Taken together, they have five main functions: illustrative, allegorical, organizing, effective, and self-reflexive. The following subsections present examples of the intersections and arguments why these intersections are functional-and thus why the fictional narrative is not an end in itself.

\section{Illustrative: Form Is Content}

What used to be called content and form/expression/representational scheme has been recognized as entwined (see Rorty 1979). What would once have been called the "form" of the book bears some of its arguments in two respects.

First, the data illustrate that the traditional journalistic objectivityas-a-norm (Carpentier and Trioen 2010), including the commitment to detachment, neutrality, and impartiality (Deuze 2005), is neither 
feasible nor desirable. Likewise, the nature of the form challenges the established traditional positivist-realist approach to objectivity, which "argues that research reports should present objective facts, established by scientific methodology, and that values should be left out of the report" (Ezzy 2002: 148). The kind of writing employed in this book, as an "emergent method," questions such an understanding of research accounts and explores the borders of knowledge (Hesse-Biber and Leavy 2008: 12).

The particular tactic of unifying the form and content is based on the assumption that there are some parallels between social-scientific and journalistic norms; for example, both journalists and academics think objectivity is attainable and desirable (although each of the groups defines it slightly differently; Post 2015). By writing in both fictional and factual genres, I attempt to stress that journalism, like science, cannot and need not mirror hard facts in an objective, non-committed, detached, factual, neutral, impartial manner. Journalism, like science, necessarily involves subjectivity, commitment, emotional engagement, values, and preconceptions. As Sam would say, journalists have to stick to the facts, and/but as Franks would say, emotion is one of the facts. Clifford Geertz and Gérard Genette would talk in a similar manner about science:

The pretense of looking at the world directly, as though through a one-way screen, seeing others as they really are when only God is looking, is indeed quite widespread. But that is itself a rhetorical strategy, a mode of persuasion. (Geertz 1988: 141)

this 'objective' kind of narrative seems to me as typically fictional as the other 'subjective' kind, and together these two symmetrical forms of focalization characterize fictional narrative, as opposed to the ordinary attitude of factual narrative, ... 'omniscient' narrative is even less verisimilar than the other two types, logically speaking. (Genette 1990: 762-763)

Thus, by adding the fictional level, I attempt to emphasize that the detached, aperspectival notion of objectivity is not plausible and disturb the notion in practice by stressing an individual perspective (that of James). Journalists, like scientists, necessarily speak from a certain perspective (which should not lead us astray into ontological relativism; Fay 1996).

Second, the form is the content by illustrating the account reconstructed based on the ethnographic data. In other words, the fictional 
narrative serves as an allegory of the real journalists' emotional development under crisis circumstances. This function deserves to be further expanded upon and explained.

\section{Allegorical: Thicker Than Thick}

The whole fictional narrative is an allegory consisting of several metaphors $^{1}$ : for example, the catastrophe at San Lorenzo, ice-nine, freezing, James, and the journey. The time has come to take the metaphors down. To explain them bluntly:

- The fictional narrative alludes to Kurt Vonnegut's dystopic novel Cat's Cradle, first published in 1963 (Vonnegut 2011).

- As in Cat's Cradle, San Lorenzo refers to a fictional Caribbean island; the ice-nine, developed by the Manhattan Project, stands for a solid structure of water that, when contacting liquid water, turns its molecules into molecules of ice-nine (the ice-nine kills instantly when brought into contact with soft tissues); the catastrophe then expands globally by freezing the world's oceans, which Vonnegut uses as a plot device.

- The process of freezing is a metaphor of one of the ideal-typical emotional developments of journalists, the process of becoming cynical.

- The development itself is represented by the metaphor of a journey-namely, the flight.

As a whole, James' journey, his mental states, starting with not-sounpleasant excitement, shivers, curiosity, and pop-up personal memories, and ending with the hectic drafting of a report, immersion in technological details, and working on suppression of his physiological needs, his goal-arriving at a frozen island hit by the worst of crises-his admiration for his role model, and so on, all together form an allegory of the interviewees' retrospective reconstructions of their emotional development. (The soundness of the allegory was "validated" by Sven, who, after reading James' story, said that 20 years ago he was exactly like James, and

\footnotetext{
${ }^{1}$ The difference between the two poetic devices being that while metaphor is a single figure of speech that translates meaning between two particular things, suggesting their nonliteral similarity, allegory is extensive and coherent and works at the level of the whole story or text (Mirvaldová 1972).
} 
started to recall specific moments: e.g. traveling by car across Kosovo with other journalists reporting on the Kosovo War.)

There are many less substantial and partial metaphors, as well. In particular, what happens in the fictional story is very often a metaphor of developments of the factual study. Let me cite an example:

He heard the robotic flight attendant's voice emanating from speakers, and took off his headphones. "... and the number is constantly growing," she just said, most probably informing the passengers of the latest developments at San Lorenzo. The audience reacted by deafening silence. The voice was waiting for questions. No questions were coming. Was it anxiety, or apathy (Van Loon 2002)? Probably both, James thought. It took less than half of a second, and the same flight attendant suddenly emerged from behind, imperceptibly singing a joyful tune with a hint of melancholy and striding towards the nose. Someone cut through the silence with a question. James rather aimed his attention back to the technologies.

This unfolds when the data illustrate the magical, surreal character of crisis reporters' experience (shaped, among other things, by technology), particularly the multiplication of their selves (i.e. the fact that they simultaneously exist physically and on screens, here and there, in Europe and in conflict zones). Similarly, the flight attendant's voice is still waiting for passengers' questions while her body marches around. Furthermore, the piece of text implicitly reflects upon the possible dealing with existential questions and ontological insecurity triggered by the sense of the surreal. The metaphor thus enables me to suggest the unspoken and to address diverse issues in one single image.

The fictional part of the narrative thus allows me to allegorically express complex meanings, tensions, and alternate viewpoints. As Milan Kundera (1988) wrote in The Art of the Novel, complexity is the novel's spirit; the novel says to the readers that things are more complex than the readers think they are. In addition, it "offers a method for following and actively pursuing our 'hunches' in order to see where they take us" (Hesse-Biber and Leavy 2008: 4-5).

\section{Who Is James?}

In this context, the metaphor of James holds a special position. On the one hand - and most of all — he is an ideal-typical figure and his personality traits are borrowed from the real-world interviewees, although his character is rather a personification of a subset of the interviewees' younger, less 
experienced, child-free selves (see Sven's reaction to James above). He is an idealist-his criticism and his insistence on certain principles echo some of the reporters' thoughts. At the same time, he cannot deny that the catastrophe, together with the mythic haze of crisis reporting, arouses him. Consider the following excerpt:

Going to San Lorenzo, he said to himself aloud. It immediately occurred to him that he must have seemed ridiculous to the young woman that was still two steps behind him. Everyone here was going either to San Lorenzo, or to one of the neighbouring islands that were expected to be contaminated by the ice-nine very soon-long before their arrival. For a second, the nervousness he experienced was bodily again. He shivered, felt the urge to erupt into laughter, and jump, pull a face or cry.

Only after James had "wised up" to the not-so-exceptional nature of his experience was he able to suppress his bodily movements and uncontrolled manifestations of nervousness. Thus, the excerpt also illustrates the normalization of crisis (Pedelty 1995). Later, he would get tougher, like the interviewees did, especially if he were to have children:

The birth of my first child was an absolutely essential moment that formed me as a journalist. Because it, at the best moment, kicked my ass and shot me down from the ... bumptious journalistic cynicism of a young journalistic nitwit. (Vítek)

This makes James' initial mind-set and the way he comes out a metaphor for the typical path journalists follow during the emotional development and a core of the allegory as a whole.

Moreover, James' gendered experience and minimalist, unpromising love life points the way toward telling a typical personal story about the interviewees, whose work, gender, need for independence, ways of being in a relationship and family life often significantly interfered with each other. The reporters' stories were sometimes too intimate and/or unrelated to the main research questions to be included in the main research storyline but seemed tightly interwoven with and important for understanding the crisis reporters' emotional culture; therefore, I decided to burden James with them.

On the other hand, James' character concerns the focalization of the narrative, that is, the questions of who sees and who speaks (Culler 1997). While James is not identical to the author and the narrator, he is a bearer of the data: his thoughts and memories present my own thoughts, field 
notes, and excerpts from interviews. In other words, I follow James' recollections and construct a story based on and in dialogue with his previous experience; thus, with James we share the point of view from which a story is being told, and the fictional and the factual narratives meet in these (his/mine) collected memories (i.e. in the empirical material). The fictionality is delimited by the author's-my- direct access to James' consciousness (Genette 1990), while the factuality resides in the identity of the author and narrator and in the realness of the interviewees.

In addition, James' figure allows the expression of more than only my own position. For instance, his harshness and mockery illustrate the intellectual posture of a classical kynic (Navia 1996), so they relate to the illustrative function of the factional narrative.

\section{Organizing: Meaningful Complexity}

The fictional level of James' journey has also an organizing function. While the metaphor(s) I use allow the expression of complex meanings in a dense way, the order of the narrative-its chronology and linearity (Genette 1990)—creates a storyline that is more or less easy to follow. As Ezzy writes,

The task of writing is to reconstruct this multifaceted, multidimensional ball of information into a linear story with a beginning, middle and end. The written report cuts a single line, or thread, through the complex ball of understanding. The best writing achieves this task of providing a wellwritten story while retaining a sense of the complexity and nuance suggested by the image of the ball of understanding. (Ezzy 2002: 139)

James' retrospective of his previous experience thus enables me to organize the story of the ethnographic data into a meaningful discourse and impose a linear order on the data and related literature (see Culler 1997). Although a particular order is not, in principle, specific to either fictional or factual narratives (Genette 1990), James' story helps to stress the talelike character of ethnographic writing (Ezzy 2002) and, through the use of metaphors, retain the sense of complexity.

\section{Effective: Less Boredom, More Engagement}

A well-organized narrative is also potentially more reader-friendly. The same applies to using the fictional narrative in general: writing in the style of creative nonfiction makes research reports less boring (Caulley 2008). In particular, realistic details further conjure emotions and images in readers. 
In turn, the creative style potentially makes the research accounts more read and those who read them more engaged. According to Asleigh Watson,

novel writing presents sociologists with a process and medium through which they can expand their work for a more public, engaging, affective, and panoramic sociology. ... Sociological novels work to bring the local and global into dialogue, and may help achieve the scope and panoramic depth that sociology requires. (Watson 2016: 431)

Watson argues that interlocutor engagement and knowledge exchange are some of the key strengths of creative nonfiction. Indeed, when I asked the interviewees to comment on the draft version (see later in this chapter) and pointed out the "experimental" nature of the text, some of them expressed interest in the way it was written that, allegedly, increased their desire to read it. As researchers from the Dart Centre have illustrated, raising awareness of psychosocial risks itself can make a difference:

Situations in which staff are exposed to unexpected, disturbing content sometimes result from a lack of organisational awareness about the traumatic impact of content in general and/or from shoddy and inappropriate workflows. ... This [has] a more traumatic impact upon them as opposed to when they [are] warned in advance, for example, that they would be viewing a massacre. (Dubberley et al. 2015: 22)

In short, if the journalists are more interested in the research due to the fictional narrative, the word can spread slightly further and better raise awareness of psychosocial risks among journalists and newsroom and media managers. In Bauman's words, the awareness itself and seeing alternatives can be deployed "in the fight against the social sources of all, even the most individual and private, unhappinesses" (Bauman 2000: 89).

Such an aspiration also raises the question of engagement. The research is engaged. With Boltanski (1999; see the section "Moral Dilemmas and Guilt"), I consider it impossible to see journalists' work-related troubles without taking action, if only in the form of committed speech. (This is related to the illustrative function: the book also argues that journalists should not be directly or indirectly asked to sacrifice their humaneness.) Together with Bauman, who writes that "A non-committal sociology is an impossibility" (Bauman 2000: 89), I can see only one way of doing sociology. 


\section{Self-Reflexive: Some Intimate Excerpts}

Last but not least, the fictional narrative is infused with moments that have a self-reflexive meaning and function, albeit they often give only a hint that needs to be further explained. Most importantly:

a. James looked out the window. In the distance, he saw the last passengers of a just-landed flight striding into the airport building. A tall, slim man was leading two little children by the hands. Nostalgia for his father overwhelmed him-his childish sense of humor, silent conspiratorial bursts of laughter, his huge warm, dry, lined palms that he used to put on anthills when James was a little boy; ants would climb up his hands - the swarming astonished James; and his habit of shaking the walnut tree in the garden, so that James could pick up the nuts. It was more than a year since his father passed away.

Losing him led James into an even greater need for independence. And, here he was: ready to make good use of it. Although the pain was still stabbing.

The scene refers to a particular moment when my personal life became directly entangled with the research process. While I was conducting participant observation at $\check{C} T$ in December 2015, my own father had a sudden, very serious, life-threatening health problem. He found himself in "crisis"-in the initial meaning of the word-together with the whole family. For several very intense days and long anxious weeks and even months, we did not know if he would survive. The event affected the fieldwork in at least two ways: not only was I unable to work for some time but also asking my interviewees about the meaning of crisis became very hard and painful. At the same time, the situation revealed the humaneness and empathy of some of the research participants and inevitably and irretrievably changed my researcher's image. For example, I remember calling Čestmír, crying, telling him about my father, canceling an interview, and postponing the field work. After I became able to work again, he was very helpful and our interaction became more personal.

b. While putting his worn carry-on suitcase into overhead storage, James saw her face. The young woman who had always been two steps behind him was now sitting right in front of him. No doubt it was her. Sophie Schlesinger, the crisis reporter. He saw her yesterday on TV while watching the first flashes on the San Lorenzo catastrophe. 
(...) She was always equipped with thorough knowledge of the context. Taken together, it gave the impression that she was gifted by some preternatural capabilities.

In fact, it was she who inspired James not only to become a journalist, but, which is crucial, to try to do his best. But most importantly-and this was something that James did not realize-her somewhat moral and responsible approach to the profession was what kept alive James' hope for the existence of some basic values and principles. And now, she was sitting here, toughing it out.

The character of Sophie Schlesinger is modeled on a combination of Sophie Thunus, my colleague at Centre de recherche et d'interventions sociologiques in Liège, a running partner with whom I shared the office, and Eva Ślesingerová, my Czech supervisor. Meetings with both brilliant women strongly impacted my enthusiasm and curiosity, and their general approach to research—very ethical and dutiful—shaped my own ideals.

c. Y was one of those who stayed in James' life even after they were no longer colleagues. They became friends-or something like that. They once went for a beer after work and ended up talking about French poststructuralists, which apparently happened to create an implicit alliance-even before they knew "it" about each other. In the months and years that followed, they used to meet every now and then, holding existentialist conversations (that proved to be even more binding).

This and other mentions of James' "friends" refer to the inseparability of my own personal and professional contexts. Some of the interviewees turned into friends - mainly Sven, but also Matouš, Tobiáš, Ida, and Pavel, and I stayed in contact with many others. Seen from the opposite perspective, I got to the ethnographic sites and gathered contacts to the reporters through unrelated professional and personal networks (although I never "observed" my previously existing friends; see more on the access to the media organizations below). While friendship in ethnographic enquiry can cause confusion of roles (Hendry 1992), the friendships entangled with the fieldwork I conducted happened to be rather of benefit to the research. For example, they have allowed me to discuss the findings and exchange interpretations and ideas with practical experts in the field.

The following section deals with self-reflection in a more systematic way. For one more story-this time fully factual-needs to be told. 


\section{The Research Method}

\section{Establishing the Field}

This research monograph is based on my Ph.D. research that started in 2014. In early spring 2015, I changed my supervisor and was rethinking the initial research project on media and anomie. The new supervisor, or "consultant," suggested that I could simply go to a newsroom for a few weeks and see what to focus on.

I did so, opportunistically using my previous professional networks as sources for research ideas and data (Riemer 1977). I used to work for Czech Television (not in reporting but as PR support for a small unit producing documentaries and experimental TV shows), so I contacted a former colleague, who redirected me further to his superiors. They granted me access to the newsroom of the Czech TV web news service.

Czech TV (Česká televize; $\check{C} T$ ) is a Czech public service broadcaster running six channels, including a 24/7 news channel, and an online news service. It was created in 1992 from its Czechoslovak antecedent and operates in Prague, Brno, Ostrava, and all regions of the country. In the Prague headquarters where I conducted the fieldwork, there are a number of specialized newsrooms. Being funded mainly by television fees (set by an Act of Parliament), it has roughly a 7 billion CZK (roughly 272 million EUR) yearly budget and remains independent of the state budget and the state, although the Czech Television Council that controls the activities of Czech TV is elected by the Chamber of Deputies.

The newsroom of the online news service, selected like the other research sites (see below) partly opportunistically, partly based on pragmatic considerations, and partly on the basis of foreshadowed research problems (Hammersley and Atkinson 1995; Riemer 1977), thus became the first site of my ethnographic enquiry. It consisted of about 15 writing journalists (each of them focusing on a certain range of topics), sometimes lacking desks, chairs, computers, screens, and other equipment. It was situated in a high-rise building that forms a part of $\check{C} T$ headquarters.

I started to perform what Martyn Hammersley and Paul Atkinson (1995: 1) define liberally as "participating, overtly or covertly, in people's daily lives for an extended period of time, watching what happens, listening to what is said, asking questions," including long-term intellectual, intuitive, physical, emotional, and political immersion (Amit 2000). I used to sit at different spots in the newsroom (depending on the taken desks) and participated in newsmaking. Although the media professionals knew I 
was a researcher and had been acquainted with the research topic, I was lucky that they treated me like an intern (cf. Czarniawska 2011). They authorized me to prepare online news content and write articles, gave me counsel, and in a few cases even minutely examined my writing attempts.

Embodied in the fieldwork were qualitative interviews ranging from semi-structured to less structured, in-depth, and narrative conversations between a journalist and me in the role of a researcher (Arksey and Knight 1999). During this early research period, I conducted five research interviews and had many smaller talks about making crisis news and using technology.

The data I reconstructed during this early stage of the research were rich and messy, but the phase proved to be essential for constructing the field. As Vered Amit writes,

the ethnographic field cannot simply exist, awaiting discovery. It has to be laboriously constructed, prised apart from all the other possibilities for contextualization to which its constituent relationships and connections could also be referred. This process of construction is inescapably shaped by the conceptual, professional, financial and relational opportunities and resources accessible to the ethnographer. (Amit 2000: 6)

Indeed, I entered the newsroom with sensitizing preconceptions of "crisis" as an event outside-the-media (Olsson and Nord 2015) and a somewhat vague but rather neo-materialist understanding of "technology." These sensitizing concepts guided my observations and alerted me to some important situations (Bowen 2006). Most importantly, their initial understanding helped me to construct an ever-changing interview guide (Arksey and Knight 1999). However, the sensitizing concepts and the research problem were to be improved and refined, as their survival depended on the data (Bowen 2006). As Hammersley and Atkinson write,

the nature of the setting may still shape the development of the research questions. This arises because ... in ethnographic research the development of research problems is rarely completed before fieldwork begins; indeed, the collection of primary data often plays a key role in that process of development. (Hammersley and Atkinson 1995: 37)

Eventually, while both concepts, "crisis" and "technology," provided a good starting point for building analysis, they survived in a thoroughly redefined way (see the "Ending"). I left the newsroom with a more 
Foucauldian understanding of technology, taking into consideration circulating power (Foucault 1988) and a confused view of crisis.

But most importantly, analysis of the early data gave rise to emotions as a third conceptual axis of the research. I was taken by surprise by the blackness of the journalists' humor and by the eagerness the research participants showed when something, no matter how negative, happened. As Viktor said, "Things like floods, I terribly enjoy them. Finally, something is going on! Floods are journalistic Olympics." These contrasting, up-anddown emotional fits seemed significant, theoretically, practically, morally, methodologically resonating (see Tracy 2010), and fascinating.

Thus, the initial phase enabled me to clearly delimit the research problem: technological shaping of journalists' emotional experience in crisis situations. I wanted to know:

1. What does "crisis" in "crisis reporting" mean?

The journalists' experiences and perspectives were primary here: it seemed that by living inside-the-media rather than with the media (Deuze 2011), they also lived inside crises and inside the logic of organizational and psychological needs of crisis moments outside-the-media (Olsson and Nord 2015). Many of them also bore the weight of the immediate crisis of modernity/risk society (Wagner 1994; Beck 1992; Giddens 1991), as they were constantly being reminded of the possibility of mass death and destruction. It seemed that this kind of life and need was crucial for their emotional experience and development.

2. What is crisis reporters' emotional experience?

The experience of life inside a milieu delimited by so many levels of crisis-ness needed to be further explored and described. Thus, I posed the question, what were the journalists' immediate emotional responses and where did they lead in the journalists' own sensemaking, long-term perspective (Weick 1995)?

3. How does technology articulate journalists' emotional experience of crisis?

It was clear from the early data that the journalists' emotional development was influenced not only by the ubiquity of crisis but also by the logic 
of newsmaking and the journalistic job in general: by routines and devices, work with words and images, existing journalistic norms and organizational practices, and the ways in which the journalists worked on their selves accordingly (Foucault 1988). This made it possible to study their emotional experience as emotional labor (Hochschild 1983).

The core of the interview guide thus revolved around the three concepts (Arksey and Knight 1999); nevertheless, I always adjusted some of the questions based on each individual's specific typical tasks (e.g. regions she covered) and particularities of experience (e.g. an emotionally powerful, life-threatening situation, or reporting on a crisis close to home). Likewise, the observations gradually became more focused. Narrowing the research aim on the way and specifying the interview guide and things to pay attention to during participant observation after entering the first newsroom proved to be vital for meaningful coherence of the study (Tracy 2010). Such "a continuous movement between pre-existing interpretive frameworks, both theoretical and popular, and the data of observation, collected during both intentional observation and everyday life" (Ezzy 2002: 25) then characterized the whole research process.

\section{Immersion in the Research Problem}

After spending the first few weeks in the newsroom of the online news service, I knew it would be valuable to come closer to reporters with more hands-on experience. The contacts I had made in the high-rise building helped. I wrote a formal e-mail to the head of news, asking for access to the core $\check{C} T$ newsrooms and simultaneously applied for a job with a team of beginning reporters. In two weeks, I received a phone call from the team and permission to start my fieldwork among the novices in November 2015. However, two days after the fieldwork started, I arranged a meeting with the head of the foreign affairs desk and was allowed to sit in the control room next to the primetime news anchors and experienced media professionals working on foreign affairs news. I spent with the (about 20) foreign affairs reporters two almost full-time months (although the incident with my father somewhat shortened the actual period of time). Since I lacked the necessary skills to make reportage, I observed without participating in the newsmaking practices (Hammersley and Atkinson 1995; cf. Czarniawska 2011) but with participating in some meetings (of both the foreign affairs desk and the news in general) and informal moments (coffee and smoking breaks). 
The fieldwork overlapped with several crisis moments and states: most importantly, the terrorist attacks in Paris in November 2015, the so-called refugee crisis, and the shooting down of a Russian jet fighter by the Turkish army (with unpredictable consequences). These tragic events made me a direct, real-time witness of the journalists' practices of crisis reporting and the newsroom rush, which made the research process opportunistic in yet another sense (Riemer 1977).

I also conducted ten interviews with foreign news reporters, including flying or parachute reporters (Cottle 2009) and foreign correspondents. I sought to interview primarily journalists, reporters, and foreign correspondents who had extensive direct experience with crisis reporting. It was here that the category of "crisis reporter" emerged. The label denotes simply "journalists involved in crisis reporting" (Neumann and Fahmy, 2016: 227) and defines the journalists by what they do without claiming that "crisis reporter" is a pre-established sort of person (Latour 2005) or a standardized professional segment. However, some of the journalists bore traits of Mark Pedelty's "war correspondents": cool renegades living an adventurous, independent, brave life (Pedelty 1995: see pages 24 and from 29 on).

Additionally, I traced everything else that seemed to be important and accessible. Occasionally, I took photos of the site, read relevant documents, such as legal acts and internal guidelines for crisis reporting, and followed the social media accounts of some of the interviewees and other research participants. I also read their stories online and watched their reports on TV (although I did not conduct analysis of media content, as analysis of media representations would not address the research questions).

In late January 2016, not long after the fieldwork in the $\breve{C} T$ 's control room, I left for Liège, where I planned to conduct interviews.

My ethnographic study was becoming more and more multi-sited, approaching the research problem rather as a European or global phenomenon than as a locally bounded problem. George Marcus explains:

multi-sited ethnography is an exercise in mapping terrain, its goal is not holistic representation, an ethnographic portrayal of the world system as a totality. Rather, it claims that any ethnography of a cultural formation in the world system is also an ethnography of the system, and therefore cannot be understood only in terms of the conventional single-site mise-en-scene of ethnographic research. ... For ethnographers interested in contemporary local changes in culture and society, single-sited research can no longer be easily located in a world system perspective. (Marcus 1995: 98-99) 
This is the case of crisis reporting and the media in general, which is why media studies has become an important arena where this approach has emerged (Marcus 1995). As has been illustrated, the distinctions between global and local, social and individual, here and there, are untenable in crisis reporting. Also the journalists, often traveling or staying abroad, themselves saw their frame of reference rather in the professional ecosystem than in their media organization or nation-state. The multisited and multilingual approach to ethnography was thus more suitable than conventional single-sited research.

This particular form of multi-sited ethnography also excluded methodological nationalism (Beck 2007), which equates societies with nationstates and sees them as cornerstones of sociological analysis. Such a methodological habit becomes less appropriate vis-à-vis the cosmopolitan condition, related to, for example, global risks that connect actors across borders. Beck even imagines that

a cosmopolitan mixture in global sociology could give birth to a cosmopoli$\tan$ vision for the humanities [that] has a strong standing against the retrogressive idealism of the national perspective in politics, research and theory. (Beck 2007: 289-290)

Following this critique of methodological nationalism, I did not compare between nation-states and national media or journalists systematically. Comparison based on nation-state borders is included only in cases where history makes the borders significant for understanding the research problem. Such a selectivity is, I believe, legitimate not only for the sake of methodological cosmopolitism but also because multi-sited ethnography is marked by inevitable asymmetry in quantity and intensity of data reconstructed by varied fieldwork practices employed at the individual sites (Marcus 1995).

In Belgium, I conducted ten interviews (eight from March 2016 to June 2016, two additional in July 2017) with both Flemish and Walloon journalists from VRT (the Flemish public service broadcaster), De Morgen (a Flemish progressive newspaper; DM), and Le Soir (the largest Walloon newspaper; $L S$ ). Any systematic sampling proved to be impossible; I was not able to make random journalists reply to my requests for an interview, so I initially used my previous personal and professional networks and then continued with purposeful snowball sampling. While the only rationale for 
snowball sampling is ease or convenience (Ezzy 2002), I eventually happened to interview some of the most prominent and experienced Belgian conflict reporters.

The first interview took place on March 15. A week after that, on the morning of 22 March 2016, three coordinated suicide bombings occurred in Brussels: two at Zaventem Airport and one in central Brussels at the Maalbeek metro station. Thirty-two civilians and three perpetrators were killed, and more than 300 people were injured. The bombings, plotted by a Salafi jihadist militant group known as Daesh or ISIL, constituted the deadliest act of terrorism in Belgium's history.

Even if some Brusselians might have anticipated the atrocities, given that the perpetrators belonged to a terror cell which had been involved in the November 2015 Paris attacks, their first-hand experience deeply shook the city and other parts of Belgium. Many people grieved-the Belgian government declared three days of national mourning-and faced the paralysis of the country's infrastructure. For the first time in their lives, those Belgian reporters who commonly travel to conflict zones and disaster sites were suddenly tasked with reporting on a "combat zone event" that was occurring at the place where they, and their families and friends, lived. The traditional commitment to detachment, impartiality, fairness, and professional distance, concepts used by journalists and academics to revisit and re-legitimize objectivity (Deuze 2005), was challenged. It was no longer possible to be a fly on the wall; the journalists' subjective experiences as witnesses, actors, and even indirect victims merged with their professional tasks (cf. Van Zoonen 1998). Thus-besides preventing me from traveling to Prague to my grandfather's funeral- the tragedy induced me to redesign the interview guide and to pay more attention to journalistic professional ideology and to the journalists' sense of the surreal. The subsequent media hype also led to postponing the interviews, since the journalists were busier than in normal times $(\mathrm{McD}$ onald and Lawrence, 2004). We all lived and worked inside the crisis, all the more so that our occupation was concerned with the issue.

By then, the answer to the question about what was social about emotions already seemed clear (see the "Ending"). Diverse pieces of sociological and anthropological research and theory long ago proved that emotions do not belong exclusively to the domain of psychology but are a relevant and researchable theme within sociology and anthropology (e.g. Beatty 2013; Hochschild 1983; Illouz 2007; Lutz and Abu-Lughod 1990; Rosaldo 1984; Scheper-Hughes and Lock 1987), whether concerned with 
organizations and institutional power structures or the human body and biopower. However, a new question kept arising: how to study emotions?

The levels of emotions that sociologists and anthropologists deal with range from emotions expressed in face-to-face bodily and verbal communication to elicitations of unacknowledged individual and collective emotions that play a role in various encounters, from emotions triggered during research interviews to responses to a questionnaire. Emotions can be elicited from written and oral narratives, interviews, observations and participation, emotionally charged visuals, documents, or surveys (Flam and Kleres 2015).

Referring to Arlie Hochschild, Helena Flam (2015) states that it is neither possible nor necessary to make a clear distinction between "authentic" and "surface" emotions. She positions current emotional research in sociology between the purely dramaturgical/ethnomethodological (Garfinkel 1967; Goffman 1967) and psychoanalytical/biologizing/universalistic (e.g. Ekman 1999). As Flam notes, "centuries-long emotions management made it impossible to posit any clear-cut difference between 'authentic,' subjective feelings, and the prescribed" (Flam 2015: 5). Apparently, studying the gap between feelings and displays - the widening of the gap by a specific context and conditions or its intentional elaboration and narrowing, that is, reductions in emotional dissonance, problematizing emotional management, and labor-can reveal much about such major sociological themes as power relations (see Hochschild 1983; Illouz 2007). Yet the basic assumption of emotion-related research remains that "for the most part the observed emotional expressions correspond to specific inner emotional states" (Flam 2015: 8).

This study adopts the shared assumption. By, first, treating verbal and non-verbal expressions as emotion data and, second, taking into account circulating and shared emotions, it fits in between what Flam calls the unorthodox positivist-expressionist dramaturgical approach and the interactionist dramaturgical approach.

Yiannis Gabriel and Eda Ulus (2015) illustrate three different ways of expressing emotions: a person (1) declares that she feels a certain way, (2) acts in a certain way, or (3) tells a story which gives clues about how she may feel. Whether to approach emotions through interviews, that is, as narratives and retrospective sensemaking accounts, or via observations, that is, as bodily practices, is one of the most important and general dilem- 
mas in emotion-related research designs. Although some researchers argue for the latter, reflecting a somewhat Bourdieuian perspective on emotions (Scheer 2012), the narrative approach seems to dominate (see Flam and Kleres 2015). For example, Barbara Czarniawska "plead[s] for studies of the 'rhetoric of emotions,' because this is all there is and this is what needs to be known-i.e. how people speak about their own and others' emotions in different times and places" (Czarniawska 2015: 68). I decided to take the two perspectives as complementary and to combine them within a more comprehensive epistemological framework consisting in observing emotions that the actors explicitly or implicitly express or attribute to each other (Flam 2015).

On one hand, the emotional narratives allowed me to see the reporters' views of their emotional development and past experience. It follows from the research questions that I was interested not only in the immediate emotional practices of crisis reporting and their plugging into the complex of other types of news-production technology but also in a longer biographical process of adjustment to the media life. This process of widening the disruption between feelings and displays by the specific work, working context and conditions, its elaborating and narrowing - that is, managing emotions and performing emotional labor (Hochschild 1983; Illouz 2007 ) could not be studied without taking a diachronic (retrospective) perspective enabled by interviewing/recalling.

Interviewing the journalists did not give me direct access to their consciousness, but rather to how they made sense of their work-related, technologically co-shaped emotional experience. According to Karl Weick (1995, from p. 17 on), sensemaking is a retrospective, social, ongoing process grounded in identity construction. It is a process enactive of sensible environments, focused on and by extracted clues, and driven by plausibility rather than accuracy. Sensemaking, aptly expressed by the sentence "How can I know what I think, until I see, what I say?" (Weick 1995: 18), means continual redefinition of the puzzle of the sensemaker's self, based on past events:

experience as we know it exists in the form of distinct events. But the only way we get this impression is by stepping outside the stream of experience and directing attention to it. And it is only possible to direct attention to what exists, that is, what has already passed. (Weick 1995: 25) 
Furthermore, as sensemaking is social and enactive of environments, making sense of one's experience is also closely linked to an organization's image. The process thus brings together technologies of the self (Foucault 1988 ) and the construction of organizational/professional identity (Du Gay 1996), including the reconstruction of the self-myth of "crisis reporter" (Pedelty 1995). By narrating their emotional experience of crisis reporting, the journalists not only made sense of it but also constructed their organizational/professional identities and rendered sensible both their experience and their identities.

On the other hand, observing emotions meant living through the crises together with the reporters, seeing their reactions and indications of their feelings. Here, the practice of "emotional participation" (Bergman-Blix 2015; Wettergren 2015) was very helpful. Emotional participation, that is, critical emotional engagement in the field, enables the researcher's own emotions to be used as both methodological and analytical tools. First, becoming engaged in the emotions that the observed people feel enables the researcher to blend in with the site. Second, the discrepancy between the field participants' habitual emotions and the visiting researcher's nonhabitual emotions serves as an analytical clue. Making use of our own research-related emotions, after all, may appear to be the most open and ethical way of dealing with them. As Benno Gammerl (2015: 153) states, "If emotion is inseparable from cognition, then the researcher's feelings cannot be disconnected from the analytical process." All the more so that the interpretation of emotions depends largely on lay knowledge, only as it plays out against theory and expert knowledge.

In practice, my own non-habitual feelings of surprise and sympathy (see earlier in this chapter) helped me to specify the research problem. Experiencing the same emotionally charged situations as the research participants (particularly the terror attacks in Brussels) allowed me to better understand their frames of mind. Later, being nervous about newsroom deadlines and exhausted by late working hours (see later in this chapter) gave me the opportunity to experience similar bodily feelings as the research participants. Above all, talking about the emotional difficulties, perceived by many of the interviewees as intimate, would have been impossible without some level of closeness and trust.

Being more and more immersed in the field, I became aware of diverse axes of variability of the data. Besides the histories of the national media systems, the journalists' experience depended on media types (TV vs. radio vs. online news), legal status (commercial vs. public service media), 
types of crises, gender, age, ethnicity, ${ }^{2}$ duration of journalistic experience, and so on. Apart from the job, the only thing all the research participants had in common was European nationality. In this sense, the study is Eurocentric and does not take into account experiences of journalists who are at home in conflict zones. This is caused by the opportunistic design (Riemer 1977) and feasibility of fieldwork.

In June 2016, I returned to Prague for several months. After being denied access to Hospodáršé noviny (Economic Newspaper), I again deployed my personal and professional networks to get access to the foreign affairs desk of Lidové noviny (The People's Newspaper; LN), the oldest Czech printed daily. $L N$ forms a part of the media house MAFRA, since 2013 a subsidiary of the Agrofert group, owned by the then Czech Minister of Finance and oligarch Andrej Babiš. While it used to be a prestigious paper due to the number of Czech writers, politicians, and philosophers contributing to the content and its focus on foreign affairs and culture, its reputation has been recently modified by the new ownership. In accordance with the general trend in print news, $L N$ circulation has significantly decreased during the past two decades; in 2017, the circulation oscillated around 38,000 copies and 200,000 readers per issue.

At $L N$, I spent two full-time months of participant observation, during which I complied with Ezzy's claim that "Qualitative observation, and data analysis, is best done when the observer becomes part of the dance" (Ezzy 2002: xxi). After the first few days of getting the feel of the newsroom and newswork, the foreign affairs reporters loaded work on me. I was allowed to write articles and put forward topics like the others; I even received press credentials (Image 6.1).

We also used to eat together in surrounding restaurants. Over lunches and coffees, I conducted eight interviews (i.e. I interviewed all the journalists in the foreign affairs department and one investigative journalist who covered the terror attacks in Paris in November 2015). Eventually, I stayed and helped in the newsroom a week longer than I had planned, in order to support the foreign affairs desk after its head left for maternity leave. At the end of the participant observation, they insisted on paying me for some of my articles. I was adamant that I did not want any money. They still insisted, their jokey argument being that I could "milk" the owner the oligarch Andrej Babiš-a bit. So I agreed.

${ }^{2}$ I use pseudonyms that reflect the media professionals' gender and ethnicity. 


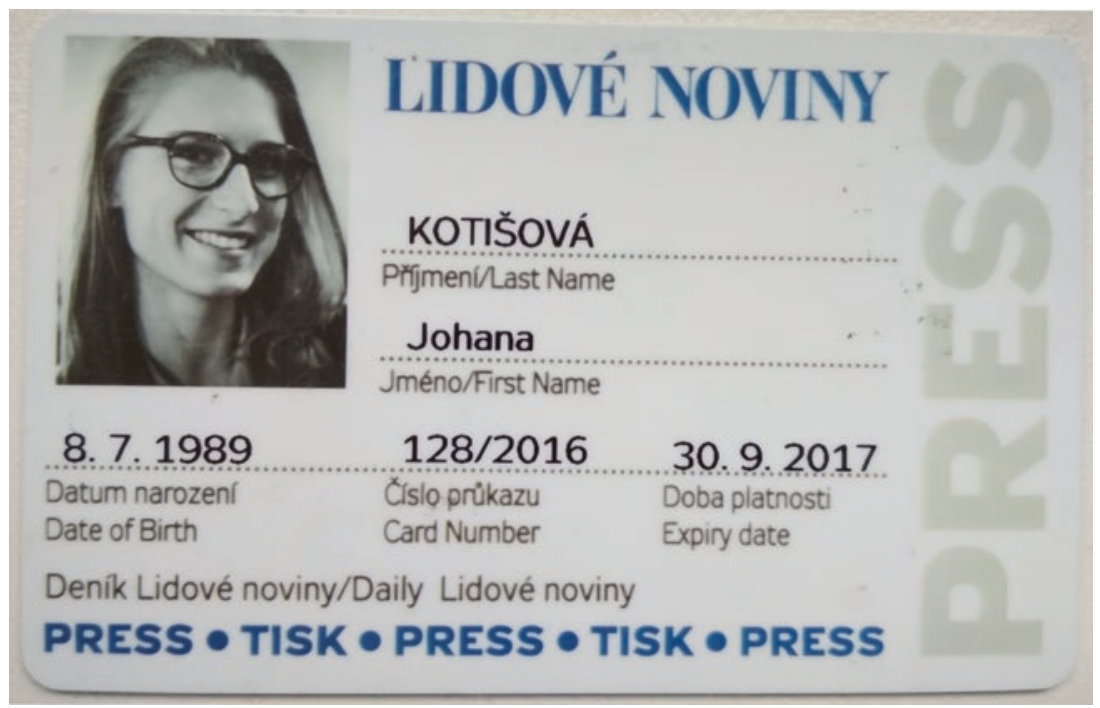

Image 6.1 The author's press credentials issued during the fieldwork in The People's Newspaper, Autumn 2016. Picture taken by the author

While at $\check{C} T$, I was taking field notes during the observation, and thus was able to describe the field rather thickly even on the fly, in contrast at $L N$ I was busy writing stories, so I made only brief notes during working hours (at both $\check{C} T$ and $L N$, I was present from about 9.30 or 9.45 a.m. to 6 p.m., including a few weekends), and always wrote everything down in the evening, at night and on "days off."

After returning to Belgium in October 2016, I occasionally turned into a "special correspondent from Brussels" and wrote (paid) reports from the European Council and the Dutch elections. The people at $L N$, having no permanent correspondent in Belgium, were glad that they could publish a report based on on-the-spot experience; I was glad about staying in the field and even merging with it (some of the events I reported lasted until late evening, and so I got acquainted with the stress and rush before deadlines). It was also a unique opportunity to meet other foreign affairs reporters and discuss my research with them. In addition, I liked the idea of working on EU-related media content, which, I think, is underrated in the Czech media. Anytime I traveled back to Prague, I went for lunch with the "colleagues" from $L N$ (most of whom, however, do not work there 
any more at present). Such a "melding of personal and professional roles in ethnographic fieldwork" makes for an experience "which cannot readily or usefully be compartmentalized from other experiences and periods in our lives" (Amit 2000: 7).

\section{Disentanglement}

Taken together, the observations and interviews provided a great amount of rich research material.

All the interviews were recorded; each of the interviewees was given a signed informed consent form, stating that by providing the interview, she agrees with its recording and non-commercial usage. Handing the informed consent forms out rather than having them signed by the interviewees and keeping them for myself seemed to be a much better strategy for trust building, which was vital for talking about intimate experiences. The interviewees were also guaranteed the possibility to withdraw from the research project at any time, and by staying in contact with most of them, the consent has been constantly renegotiated (see Sin 2005). Last but not least, the informed consent guaranteed anonymization of the data. First, I withheld only the interviewees' names but systematically kept their affiliations unconcealed. After I was notified by an interviewee and a reviewer of one of my papers that some people might be recognizable, given that the scope of both the media systems is limited, I decided, in the most sensitive cases, to also withhold the affiliations or to unlink the pseudonyms and media organizations by using letters instead of pseudonyms. The interviews were always transcribed (some of them with a help from a Master's degree student in sociology from Masaryk University).

The analytical process was driven by what Corbin and Strauss (2007) call selective and axial (rather than open) coding. As mentioned above, the data collection and analysis were integrated, allowing the analysis "to be shaped by the participants in a more fundamental way than if analysis is left until after the data collection has been finished" (Ezzy 2002: 61). Anytime I had a new transcript or a file of field notes, I added them to Atlas.ti and coded, which allowed me to constantly refine the focus of the research. At the same time, I began with codes derived from the literature but was constantly comparing them against the actual data and revising them, as I believed that "[c] onducting data analysis during data collection results in a more sophisticated and subtle analysis" (Ezzy 2002: 78). The final set of codes was largely asymmetrical and overlapping. 
While the emotions narrated in interviews that are subject to sensemaking (Weick 1995) were easy to code, the coding of witnessed emotions was inspired by Julian Bernard's strategy to subjectively interpret others' conduct, verbal and bodily expressions of what we see as a particular emotion (Bernard 2015).

At some point, I decided the study had reached relative saturation (Ezzy 2002), and the analytical process started again. In the end, I regrouped the data based on the relationships of assigned codes to the meaning of "crisis" in "crisis reporting," the emotional experience, and the four levels of technology, in order to let the research findings tell a story (Corbin and Strauss 2007). A few codes were left out as either too detailed or redundant.

To ensure credibility, to enhance procedural and relational ethics (Tracy 2010), and to make the research practice more democratic (Ezzy 2002), I attempted to include the participants in all the phases of the research process. Starting in February 2017, I occasionally sent drafts of (parts of) the study and related articles to those research participants who had told me they were interested or with whom I was in contact. Several times, I received a valuable comment that led to reinterpretation of the data. Finally, in August 2017, I sent the whole draft version without "Ending" to all the interviewees and suggested they read it, to check the interpretations, to comment on anything in the draft, to propose changes, and, primarily, to propose their own vision of the "Ending." (The question that the interviewees saw at the end of the draft instead of a conclusion was "What should happen with James after landing?"). I asked them to send me any comments in late September 2017.

Some of the interviewees wrote me they were interested in the experimental form. Some found the text readable, and even "enlightening." Some acknowledged its accuracy and stressed points and figures that they found particularly familiar (e.g. James, individual jokes, but mainly cynicism as such). Two of them proposed a small shift in interpretation of a specific quote. Only three stuck to the deadline.

Many journalists either wrote me they would not have time to read it or did not reply. They, like James, were busy making news.

\section{Return}

The last act of the research process began in autumn 2018, when one of the reviewers of the Ph.D. dissertation-based draft of this book recom- 
mended that conducting some interviews with European reporters from countries other than Belgium and Czechia could potentially make the book more relevant for a wider audience.

Conducting an additional 14 interviews between mid-November 2018 and mid-January 2019 with Spanish, Danish, Slovak, Dutch, French, German, Italian, Swedish, and Croatian media professionals (typically print/radio/TV reporters, but also a photographer) specialized in crisis zones or in trauma issues, respectively (Judith, Tim, Finn), did much more than that.

Unlike most of the Belgian and Czech interviewees, many were freelancers or independent media professionals. Finding themselves half outside the system of media organizations, their precarity was generally higher and their criticism of mainstream media practices was scorching. At the same time, the diversity of the societies they came from was reflected in the diversity of their gendered experience. Thus, meeting them (albeit in many cases not in person but via Skype, telephone, or various applications $^{3}$ ) allowed me to include new issues, reflect upon a greater diversity of hierarchies, and re-write the text accordingly.

Like the previous cohorts, the last group of media professionals got the opportunity to comment on the new draft. This time, I received more reactions. Some of them were signed by "Anthony" or "Gloria" instead of by the real names of my communication partners. None of them suggested any changes.

\section{REFERENCES}

Amit, V. (2000). Introduction: Constructing the Field. In A. Vered (Ed.), Constructing the Field: Ethnographic Fieldwork in the Contemporary World (pp. 1-18). London: Routledge.

Arksey, H., \& Knight, P. (1999). Interviewing for Social Scientists: An Introductory Resource with Examples. London: SAGE.

Bauman, Z. (2000). On Writing: On Writing Sociology. Theory, Culture and Society, 17(1), 79-90.

Beatty, A. (2013). Current Emotion Research in Anthropology: Reporting the Field. Emotion Review, 5(4), 414-422.

Beck, U. (1992). Risk Society: Towards a New Modernity. London: SAGE.

\footnotetext{
${ }^{3}$ Therefore, in most cases of this late phase of the research, the assurance of anonymity and of ethical use of the interviews took place electronically, without using standard consent forms.
} 
Beck, U. (2007). The Cosmopolitan Condition: Why Methodological Nationalism Fails. Theory, Culture and Society, 24(7-8), 286-290.

Bergman-Blix, S. (2015). Emotional Insights in the Field. In H. Flam \& J. Kleres (Eds.), Methods of Exploring Emotions (pp. 125-133). London: Routledge.

Bernard, J. (2015). Funerary Emotions: Categorizing Data from a Fieldwork Diary. In H. Flam \& J. Kleres (Eds.), Methods of Exploring Emotions (pp. 172-180). London: Routledge.

Boltanski, L. (1999). Distant Suffering: Morality, Media and Politics. Cambridge: Cambridge University Press.

Bowen, G. A. (2006). Grounded Theory and Sensitizing Concepts. International Journal of Qualitative Methods, 5(3), 1-8.

Carpentier, N., \& Trioen, M. (2010). The Particularity of Objectivity: A Poststructuralist and Psychoanalytical Reading of the Gap Between Objectivity-asa-value and Objectivity-as-a- practice in the 2003 Iraqi War Coverage. Journalism, 11(3), 311-328.

Caulley, D. N. (2008). Making Qualitative Research Reports Less Boring: The Techniques of Writing Creative Nonfiction. Qualitative Inquiry, 14(3), 424-449.

Corbin, J., \& Strauss, A. (2007). Basics of Qualitative Research: Techniques and Procedures for Developing Grounded Theory. London: SAGE.

Cottle, S. (2009). Global Crisis Reporting: Journalism in the Global Age. Maidenhead: Open University Press.

Culler, J. (1997). Literary Theory: A Very Short Introduction. Oxford: Oxford University Press.

Czarniawska, B. (2011). Cyberfactories: How News Agencies Produce News. Northampton: Edward Elgar.

Czarniawska, B. (2015). The Rhetoric of Emotions. In H. Flam \& J. Kleres (Eds.), Methods of Exploring Emotions (pp. 67-78). London: Routledge.

Deuze, M. (2005). What Is Journalism? Professional Identity and Ideology of Journalists Reconsidered. Journalism, 6(4), 442-464.

Deuze, M. (2011). Media Life. Media, Culture and Society, 33(1), 137-148.

Du Gay, P. (1996). Consumption and Identity at Work. London: SAGE.

Dubberley, S. et al. (2015). Making Secondary Trauma a Primary Issue: A Study of Eyewitness Media and Vicarious Trauma on the Digital Frontline. Eyewitness Media Hub. Retrieved from http://eyewitnessmediahub.com/research/vicarious-trauma.

Ekman, P. (1999). Basic Emotions. In T. Dalgleish \& M. Power (Eds.), Handbook of Cognition and Emotion (pp. 45-60). New York: John Wiley and Sons.

Ezzy, D. (2002). Qualitative Analysis: Practice and Innovation. London: Routledge.

Fay, B. (1996). Contemporary Philosophy of Social Science: A Multicultural Approach. Oxford: Wiley-Blackwell. 
Flam, H. (2015). Introduction. In H. Flam \& J. Kleres (Eds.), Methods of Exploring Emotions (pp. 1-21). London: Routledge.

Flam, H., \& Kleres, J. (Eds.). (2015). Methods of Exploring Emotions. London: Routledge.

Foucault, M. (1988). Technologies of the Self. In L. H. Martin, H. Gutman, \& P. H. Hutton (Eds.), Technologies of the Self: A Seminar with Michel Foucault (pp. 16-49). London: Tavistock Publications.

Gabriel, Y., \& Ulus, E. (2015). "It's All in the Plot": Narrative Explorations of Work-related Emotions. In H. Flam \& J. Kleres (Eds.), Methods of Exploring Emotions (pp. 36-45). London: Routledge.

Gammerl, B. (2015). Can You Feel Your Research Results? How to Deal with and Gain Insights from Emotions Generated During Oral History Interviews. In H. Flam \& J. Kleres (Eds.), Methods of Exploring Emotions (pp. 153-162). London: Routledge.

Garfinkel, H. (1967). Studies in Ethnomethodology. Englewood Cliffs, NJ: Prentice-Hall.

Geertz, C. (1988). Works and Lives: The Anthropologist as Author. Stanford: Stanford University Press.

Genette, G. (1990). Fictional Narrative, Factual Narrative. Poetics Today, $11(4), 755-774$.

Giddens, A. (1991). Modernity and Self-Identity: Self and Society in the Late Modern Age. Cambridge: Polity Press.

Goffman, E. (1967). Interaction Ritual. New York: Pantheon Books.

Gutkind, L. (1997). The Art of Creative Nonfiction: Writing and Selling the Literature of Reality. New York: Wiley.

Hammersley, M., \& Atkinson, P. (1995). Ethnography: Principles in Practice. London: Routledge.

Hendry, J. (1992). The Paradox of Friendship in the Field: Analysis of a LongTerm Anglo-Japanese Relationship. In J. Okely \& H. Callaway (Eds.), Anthropology and Autobiography (pp. 161-172). London: Routledge.

Hesse-Biber, S. N., \& Leavy, P. (Eds.). (2008). Handbook of Emergent Methods. New York; London: The Guilford Press.

Hochschild, A. R. (1983). The Managed Heart. Berkeley: University of California Press.

Illouz, E. (2007). Cold Intimacies: The Making of Emotional Capitalism. Cambridge: Polity Press.

Kundera, M. (1988). The Art of the Novel. New York: Grove Press.

Latour, B. (2005). Reassembling the Social: An Introduction to Actor-NetworkTheory. Oxford: Oxford University Press.

Lutz, C., \& Abu-Lughod, L. (Eds.). (1990). Language and the Politics of Emotion. Cambridge: Cambridge University Press. 
Marcus, G. E. (1995). Ethnography in/of the World System: The Emergence of Multi-sited Ethnography. Annual Review of Anthropology, 24, 95-117.

McDonald, I. R., \& Lawrence, R. G. (2004). Filling the $24 \times 7$ News Hole: Television News Coverage Following September 11. American Behavioral Scientist, 48(3), 327-340.

Mirvaldová, H. (1972). Několik poznámek k rozlišení metafory, alegorie a symbolu. Slovo a slovesnost, 33(1), 18-24.

Navia, L. E. (1996). ClassicalCynicism: A CriticalStudy. London: Greenwood Press.

Neumann, R., \& Fahmy, S. (2016). Measuring Journalistic Peace/war performance: An Exploratory Study of Crisis Reporters' Attitudes and Perceptions. International Communication Gazette, 78(3), 223-246.

Olsson, E. K., \& Nord, L. W. (2015). Paving the Way for Crisis Exploitation: The Role of Journalistic Styles and Standards. Journalism, 16(3), 341-358.

Pauly, J. J. (2014). The New Journalism and the Struggle for Interpretation. Journalism, 15(5), 589-604.

Pedelty, M. (1995). War Stories: The Culture of Foreign Correspondents. London: Routledge.

Post, S. (2015). Scientific Objectivity in Journalism? How Journalists and Academics Define Objectivity, Assess Its Attainability, and Rate Its Desirability. Journalism, 16(6), 730-749.

Richardson, L. (1997). Fields of Play: Constructing an Academic Life. New Brunswick: Rutgers University Press.

Riemer, J. W. (1977). Varieties of Opportunistic Research. Urban Life, $5(4), 467-477$.

Rorty, R. (1979). Philosophy and the Mirror of Nature. Princeton: Princeton University Press.

Rosaldo, M. Z. (1984). Towards an Anthropology of Self and Feeling. In R. A. Schweder \& R. A. LeVine (Eds.), Culture Theory: Essays on Mind, Self and Emotions (pp. 137-157). Cambridge: Cambridge University Press.

Schaeffer, J. M. (2014). Fictional vs. Factual Narration. In P. Hühn et al. (Eds.), Handbook of Narratology (pp. 179-196). Berlin: Walter De Gruyter.

Scheer, M. (2012). Are Emotions a Kind of Practice (And Is That What Makes Them Have a History)? A Bourdieuian Approach to Understanding Emotion. History and Theory, 51, 193-220.

Scheper-Hughes, N., \& Lock, M. (1987). The Mindful Body: A Prolegomenon to Future Work in Medical Anthropology. Medical Anthropology Quarterly, 1(1), 6-41.

Sin, C. H. (2005). Seeking Informed Consent: Reflections on Research Practice. Sociology, 39(2), 277-294.

Tracy, S. J. (2010). Qualitative Quality: Eight “Big-tent” Criteria for Excellent Qualitative Research. Qualitative Inquiry, 16(10), 837-851. 
Van Loon, J. (2002). Risk and Technological Culture: Towards a Sociology of Virulence. London: Routledge.

Van Zoonen, L. (1998). A Professional, Unreliable, Heroic Marionette (M/F): Structure, Agency and Subjectivity in Contemporary Journalisms. European Journal of Cultural Studies, 1(1), 123-143.

Vonnegut, K. (2011). Cat's Cradle. London: Penguin Books.

Wagner, P. (1994). A Sociology of Modernity: Liberty and Discipline. London: Routledge.

Watson, A. (2016). Directions for Public Sociology: Novel Writing as a Creative Approach. Cultural Sociology, 10(4), 431-447.

Weick, K. E. (1995). Sensemaking in Organizations. London: SAGE.

Wettergren, Å. (2015). How Do We Know What They Feel? In H. Flam \& J. Kleres (Eds.), Methods of Exploring Emotions (pp. 115-124). London: Routledge.

Open Access This chapter is licensed under the terms of the Creative Commons Attribution 4.0 International License (http://creativecommons.org/licenses/ by $/ 4.0 /$ ), which permits use, sharing, adaptation, distribution and reproduction in any medium or format, as long as you give appropriate credit to the original author(s) and the source, provide a link to the Creative Commons licence and indicate if changes were made.

The images or other third party material in this chapter are included in the chapter's Creative Commons licence, unless indicated otherwise in a credit line to the material. If material is not included in the chapter's Creative Commons licence and your intended use is not permitted by statutory regulation or exceeds the permitted use, you will need to obtain permission directly from the copyright holder.

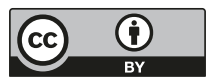

